\title{
Integrating team science into interdisciplinary graduate education: an exploration of the SESYNC Graduate Pursuit
}

\author{
Kenneth E. Wallen ${ }^{1}$ (D) - Karen Filbee-Dexter ${ }^{2}$. Jeremy B. Pittman ${ }^{3}$. Stephen M. Posner ${ }^{4,5} \cdot$ Steven M. Alexander ${ }^{6,7}$. \\ Chelsie L. Romulo ${ }^{8}$ - Drew E. Bennett ${ }^{9}$ Elizabeth C. Clark ${ }^{10}$. Stella J.M. Cousins ${ }^{11}$ • Bradford A. Dubik ${ }^{10}$ • \\ Margaret Garcia $^{12}$ • Heather A. Haig ${ }^{13}$ • Elizabeth A. Koebele ${ }^{14}$. Jiangxiao Qiu ${ }^{15} \cdot$ Ryan C. Richards $^{16}$. \\ Celia C. Symons ${ }^{17} \cdot$ Samuel C. Zipper ${ }^{18,19}$
}

Published online: 20 March 2019

(C) The Author(s) 2019

\begin{abstract}
Complex socio-environmental challenges require interdisciplinary, team-based research capacity. Graduate students are fundamental to building such capacity, yet formal opportunities for graduate students to develop these capacities and skills are uncommon. This paper presents an assessment of the Graduate Pursuit (GP) program, a formal interdisciplinary team science graduate research and training program administered by the National Socio-Environmental Synthesis Center (SESYNC). Quantitative and qualitative assessment of the program's first cohort revealed that participants became significantly more comfortable with interdisciplinary research and team science approaches, increased their capacity to work across disciplines, and were enabled to produce tangible research outcomes. Qualitative analysis of four themes - (1) discipline, specialization, and shared purpose, (2) interpersonal skills and personality, (3) communication and teamwork, and (4) perceived costs and benefits - encompass participants' positive and negative experiences and support findings from past assessments. The findings also identify challenges and benefits related to individual personality traits and team personality orientation, the importance of perceiving a sense of autonomy and independence, and the benefit of graduate training programs independent of the university and graduate program environment.
\end{abstract}

Electronic supplementary material The online version of this article (https://doi.org/10.1007/s13412-019-00543-2) contains supplementary material, which is available to authorized users.

Kenneth E. Wallen

wallenk3@gmail.com

1 Division of Agriculture, University of Arkansas System, Fayetteville, AR, USA

2 Département de Biologie, Laval University, Québec City, QU, Canada

3 School of Planning, University of Waterloo, Toronto, ON, Canada

4 COMPASS, Silver Spring, MD, USA

5 Gund Institute for Environment, University of Vermont, Burlington, VT, USA

6 Environmental Change and Governance Group, Faculty of Environment, University of Waterloo, Waterloo, NO, Canada

7 Stockholm Resilience Centre, Stockholm University, Stockholm, Sweden

8 Environmental and Sustainability Studies Program, University of Northern Colorado, Greeley, CO, USA

9 Haub School of Environment and Natural Resources, University of Wyoming, Laramie, WY, USA
10 Nicholas School of the Environment, Duke University, Beaufort, NC, USA

11 Department of Natural Resource Management and Environmental Science, California Polytechnic State University, San Luis Obispo, CA, USA

12 School of Sustainable Engineering and the Built Environment, Arizona State University, Tempe, AZ, USA

13 Department of Biology, University of Regina, Regina, SK, Canada

14 Department of Political Science, University of Nevada, Reno, NV, USA

15 School of Forest Resources and Conservation, Fort Lauderdale Research and Education Center, University of Florida, Gainesville, FL, USA

16 Center for American Progress, Washington, DC, USA

17 Department of Ecology and Evolutionary Biology, University of California, Santa Cruz, Santa Cruz, CA, USA

18 Department of Earth and Planetary Sciences, McGill University, Montreal, QU, Canada

19 Department of Civil Engineering, University of Victoria, Victoria, BC, Canada 
Keywords Collaboration · Content analysis · Graduate education · Personality traits · Program evaluation · Qualitative research

\section{Introduction}

Contemporary socio-environmental (S-E) challenges like climate change, biodiversity loss, water management, and renewable energy are multifactorial and cannot be appropriately conceptualized, defined, or examined from a single scientific disciplinary perspective. They demand the application of interdisciplinary research (IDR) and team science (TS) approaches to capitalize on diverse perspectives and knowledge domains (Palmer et al. 2016; Table 1). Several factors contribute to this demand for IDR and TS: (a) the inherent complexity and dynamism of socio-environmental interactions, (b) disciplinary perspectives that are too narrow to thoroughly address the complexity of real-world issues and questions, (c) the urgency of S-E challenges, and (d) the availability of facilitating technologies (National Research Council [NRC] 2005). Such factors also reflect an imperative to develop and evaluate organized training and research programs. Organized and structured programs can generate the IDR and TS capacity necessary to create and sustain a S-E research community capable of addressing challenges now and in the future (Clark et al. 2011). While the need for IDR and TS remains salient, the novelty of organized IDR and TS training programs requires evaluation of experiences, practices, and curriculum to assess quality and effectiveness. The imperative to evaluate IDR and TS training efficacy is particularly salient for those programs designed for graduate students, as participants are positioned to assume leadership in academic and conservation institutions in the future (Meyer et al. 2015). Here, we present a post-program assessment of a project-based TS graduate training program, separate from participants' universitybased graduate program, whose objective is to develop TS and IDR capacity: the Graduate Pursuit (GP) program administered by the National Socio-Environmental Synthesis Center (SESYNC).

To sustain a community of research and practice with the ethos and skills to produce and apply high-quality S-E science requires that graduate students acquire IDR and TS skills. Graduate students in S-E fields require opportunities to develop team-based research and collaborative problem solving skills, interpersonal and relational skills, and the skills to learn and integrate concepts from others' disciplines (Bosque-Pérez et al. 2016; Cannon et al. 1996; Graesser et al. 2018). Such opportunities facilitate the development of skills and experiences that transfer to professional practice but are uncommon in formal graduate curricula (Blickley et al. 2013; Colón-Rivera et al. 2013; Hampton et al. 2017; Tress et al. 2007). Some universitybased graduate programs provide these opportunities, and associated assessments of them are available (Graybill et al. 2006; Read and Garcia 2015). However, limitations in infrastructure, expertise, and funding constrain the prevalence and scope of university-based programs to foster and support interdisciplinary, team-based S-E research. Moreover, university-based programs tend to be developed within the existing graduate program structures, which

Table 1 Glossary of key terms

\begin{tabular}{|c|c|}
\hline Term & Definition \\
\hline $\begin{array}{l}\text { Social-environmental } \\
\text { research }(S-E)\end{array}$ & $\begin{array}{l}\text { The study of co-dependent human and natural systems, i.e., linked social and } \\
\text { biophysical systems that mutually influence one another, including their } \\
\text { structure, dynamics, and sustainability. Understanding these systems often } \\
\text { involves synthesis research that is relevant across multiple spatial, temporal, and } \\
\text { cultural contexts. }\end{array}$ \\
\hline Synthesis research & $\begin{array}{l}\text { Research approach that uses various sources of knowledge and expertise to } \\
\text { accelerate knowledge production, define new approaches or directions, and } \\
\text { integrate ideas, theories, and/or data. }\end{array}$ \\
\hline $\begin{array}{l}\text { Interdisciplinary research } \\
\text { (IDR) }\end{array}$ & $\begin{array}{l}\text { An interactive process that integrates knowledge from multiple scientific } \\
\text { disciplines and non-scientific sectors to jointly address research } \\
\text { questions/problems and synthesize knowledge. Here, we do not distinguish } \\
\text { interdisciplinary from transdisciplinary, which some view as a higher-order } \\
\text { process and others use to refer to the practice of including knowledge-users or } \\
\text { stakeholders as participants in the research process. }\end{array}$ \\
\hline Team science (TS) & $\begin{array}{l}\text { Cross-disciplinary and/or cross-sector research initiatives formed by various } \\
\text { collaborators and partners (often long-term). TS initiatives leverage the } \\
\text { strengths and expertise of partners trained and experienced in different fields to } \\
\text { co-develop, co-define, co-produce, and co-implement research questions that } \\
\text { pertain to a common or overlapping subject matter with the intent to integrate } \\
\text { knowledge. }\end{array}$ \\
\hline
\end{tabular}


position the needs and desired outcomes of the program in competition with the IDR and TS needs of the broader S-E field. In comparison with university-based programs, the GP features a unique setting and programmatic design that would be expected to generate different benefits and challenges. Identifying these benefits and challenges and placing them within IDR and TS literature directs the purpose of this assessment and its contribution to the S-E field.

Our assessment asks what strengths, weaknesses, challenges, and benefits did GP participants experience and how do these compare with previous assessments of graduate training programs? To answer this question, we use qualitative (open-ended) and quantitative (close-ended) measures to assess participants experiences, beliefs, opinions, and perceptions related to the GP. Qualitative measures and content analysis are used to explore emergent theme-related experiences with the program, their team, and their project, as well as their perceptions of IDR/TS training and skills development. Quantitative measures are used to assess beliefs about team success, integration, and comfort with IDR and TS and to examine personality traits and their relationship to success and integration, which are linked to IDR progress and outcomes (Bennett et al. 2018; National Research Council 2015). We discuss findings relative to the previous assessments of interdisciplinary graduate training programs (e.g., Golde and Gallagher 1999; Graybill et al. 2006; Meyer et al. 2015). While our assessment is exploratory, it represents an essential step towards assessing participant experiences with and perceptions of TS/IDR training and demonstrating the GP's impact on TS/IDR capacity-building. Such information is valuable to advance conversations about interdisciplinary graduate training program effectiveness, particularly as calls for IDR/TS skills and experience in the S-E field grows. Our research questions and findings are also relevant and valuable to educators and program directors who design S-E graduate curricula, as well as graduate students and early-career researchers in the S-E field currently engaging or seeking to engage in IDR and TS.

\section{Challenges and benefits of interdisciplinary research and team science}

The increased frequency of interdisciplinary, team-based research in S-E fields and, importantly, assessments of them continually improve our understanding of the hallmarks, challenges, barriers, and conditions that facilitate effective IDR and TS (Edelenbos et al. 2017; NRC 2005; Palmer et al. 2016). The NRC identified seven parallel hallmarks of and challenges to effective IDR and TS initiatives: (1) member diversity, (2) knowledge integration, (3) team size, (4) goal alignment, (5) boundary permeability, (6) geographic dispersion, and (7) task interdependence (NRC 2015). Key elements to overcome these challenges include organized research frameworks (structures) and practices that facilitate collaborative interaction (processes) (Lindenfeld et al. 2012; McGreavy et al. 2013, 2015; Wallen 2017). Awareness and application of these hallmarks and challenges are key factors that influence the success of IDR/TS initiatives and should therefore be considered and incorporated into those initiatives, yet that consideration is uncommon. Moreover, purposeful and accountable assessment of these and other factors as components of IDR and TS initiatives is a relatively recent phenomenon (Jacobs and Frickel 2009).

Past assessments show that various hallmarks and challenges listed above contribute to IDR/TS success and failure, which can be defined as the development of basic and applied research outcomes and/or increased capacity of researchers to function in IDR/TS settings. For instance, teams comprised of members with diverse disciplines, experiences, career stages, and socio-demographics are often more successful than others (Cheruvelil et al. 2014; Nancarrow et al. 2013). As caveats, team member diversity should be weighed and balanced with the ability to develop a shared purpose, agree on similar goals or incentives, and integrate knowledge from diverse domains of expertise. Regarding knowledge integration, others emphasize the importance of processes that link individual learning to research outcomes via joint problem formulation, participatory learning, and use of shared conceptual models (Heemskerk et al. 2003; Pennington 2016). Assessments also reveal interpersonal and communication skills, and the research processes that facilitate their development, contribute to positively to outcomes and experiences (McGreavey et al. 2013, 2015). Communication competencies and patterns also influence how knowledge is mutually understood, codeveloped, and synthesized, which can afford or constrain inclusivity, teamwork, and progress towards shared goals (Cheruvelil et al. 2014; Thompson 2009). Others emphasize the importance of managing interpersonal relationships and interacting personalities within teams (Bennett et al. 2018; LePine et al. 2011; Molleman 2005; Peeters et al. 2006). In practice, however, such elements and skills are often not recognized as prerequisites, and the skills to engage in or cope with them must be developed. Collectively, past assessments emphasize attention to developing and facilitating research processes that expand researchers' skills to manage individual and shared goals, interpersonal interactions, and two-way communications.

Graduate students face similar challenges with established researchers and practitioners who engage in IDR and TS. These include the following: (a) team selection and diversity (Morse et al. 2007; Newswander and Borrego 2009), (b) problem formulation and knowledge integration (Tress et al. 2009), (c) communication and interpersonal skills development (Read et al. 2016; Record et al. 2016; Tress et al. 2007), and (d) cost-benefit balance (Read and Garcia 2015). 
Graduate students also face unique challenges (Demharter et al. 2017; Rhoten and Parker 2004). These relate to their status as students and the structure of graduate programs, which prioritize disciplinary-focused research activities (Tress et al. 2009). Other scholars identify challenges related to (a) a lack of exposure to and engagement with students of other disciplines or (b) an appropriate supervision, mentoring, and pedagogical approach (Bosque-Pérez et al. 2016; Record et al. 2016). Consequently, graduate students who engage in S-E research are often challenged to balance the disciplinary depth required by their graduate program while simultaneously broadening their interdisciplinary breadth to address complex S-E issues. Though myriad challenges exist, graduate students are well-positioned to receive substantial and enduring benefits from IDR and TS experiences as they are at a formative stage of their career (Graybill et al. 2006; Moslemi et al. 2009). Moreover, IDR and TS supplement traditional graduate training by facilitating active collaborations, professional interactions, and essential skills development. As such, providing opportunities to address S-E issues via IDR and TS approaches while simultaneously lessening challenges and enabling skills development is imperative.

Assessments of interdisciplinary graduate training in a university setting suggest various best practices to lessen challenges and enable skills development. At a program-level these include the following: (a) developing a core curriculum or competencies, (b) clarifying expectations for both depth and breadth, (c) providing mentoring and mentor training, (d) ensuring (in)formal, theoretical, and experiential educational opportunities, and (e) clear communication of expectations (Meyer et al. 2015). At the individual-level, activities that facilitate the development of IDR/TS capacity include (a) facilitating interactions with external graduate faculty and students, (b) joining projects that are related to ones' dissertation subject, (c) identifying the practical relevance of a project, and (d) establishing a sense of project ownership (Tress et al. 2009; Graybill et al. 2006; Ryser et al. 2009). Numerous programs and trainings have been developed, implemented, and evaluated within existing graduate program or university structures to offer and facilitate IDR and TS. Examples of these include the National Science Foundation's (NSF) Integrative Graduate Education and Research Traineeship (IGERT), Research Traineeship (NRT) programs and derivatives such as the Applied Biodiversity Science (ABS) program (Landon et al. 2015) and the Employing Model-Based Reasoning in Socio-Environmental Synthesis (EMBeRS) workshop (Killion et al. 2018). However, few initiatives have attempted to meet IDR and TS capacity-building needs via programs independent of a university setting. In this context, the learning environment, constraints and affordances, and expectations may be distinct and manifest differently. Moreover, existing outside the university, such programs better reflect what is required and expected of S-E professionals, and to our knowledge, no assessment of such an IDR/TS graduate training program has been conducted.

\section{SESYNC Graduate Pursuit}

The National Socio-Environmental Synthesis Center (SESYNC) was established in 2011 through a US National Science Foundation award to the University of Maryland (Palmer et al. 2016). SESYNC operates as a boundary organization (Guston 2001). Its mission is "to foster synthetic, actionable science related to the structure, functioning, and sustainability of socio-environmental systems," which is achieved through several programs (workshops, training, postdoctoral fellowships). Their core program, Pursuits, facilitate the creation of S-E research teams via an in-kind support (Baron et al. 2017; Biancani et al. 2018). That is, unlike a traditional research grant, Pursuits support teams with logistic support funds - travel, accommodations, meeting facilities, collaboration space, and computational support and cyberinfrastructure - and staff that provide technical consulting and professional facilitation; Pursuits do not fund primary data collection that requires offsite fieldwork, surveys, or assessments.

The goal of a Pursuit is the creation of a highly interdisciplinary team, with members in and out of academia, which codevelops and undertakes research to synthesize diverse data and knowledge and results in findings or products that are applicable or actionable across multiple scales and sectors, with the potential to inform decision-makers. Teams range from 10 to 25 members and are supported for a duration of 18-24 months. SESYNC designed and implements a framework with several reflexive and iterative practices to foster interdisciplinary skills training and research progress over the life of a Pursuit (Fig. 1). The recursive nature of the framework allows teams to iteratively implement, practice, learn, and reexamine various stages and elements of a project (e.g., project planning, meeting agenda setting, communication strategies, or database management). While ultimately a linear process from research proposal to research product(s), the framework allows teams and individuals to revisit many aspects of the research process to increase a team's potential for success and an individual's capacity to succeed within the IDR/TS setting.

In 2014, SESYNC used this framework to initiate the Graduate Pursuit program (https://www.sesync.org/for-you/ educator/programs/graduate-programs), an experiential, IDR/ TS training program that engages doctoral students in the same manner as Pursuits. Several aspects reflect what would be required and expected of any other grant application process, i.e., developing a competitive proposal and forming a team reflective of accomplishing the proposed research. To those ends, the GP requires self-formation of teams (5-7 
Fig. 1 An outline of the SESYNC Graduate Pursuit framework: structures, processes, and practices. The GP framework proposes two main research stages (ovals) and various research structures and processes (squares): research development and training (light hue), project facilitation activities and tools (medium hue), and objective and desired outcomes (dark hue). Dash-lined arrows represent iterative processes to improve research outcomes, skills development, and team dynamics, while solid arrows represent designed workflow

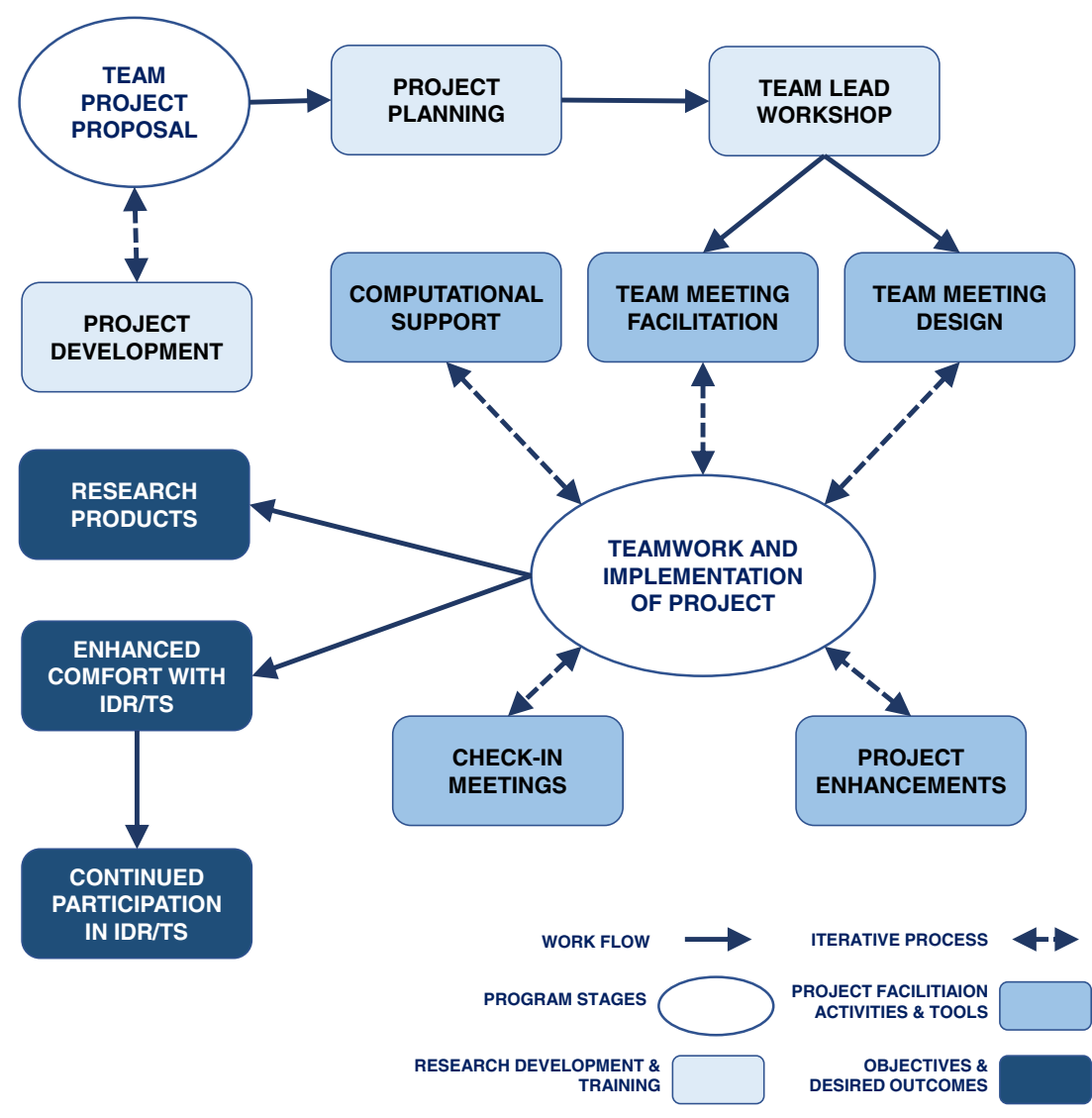

members) with diverse backgrounds and disciplines to propose, conduct, and disseminate S-E research in a TS setting. The central and distinguishing feature of the GP, in comparison with other graduate training programs, is that students independently form and lead teams and projects as principal investigators from proposal to publication. The GP is designed as a long-term (12-18 months) training program, independent of students' graduate program, wherein doctoral students conduct research while simultaneously developing and using skills necessary to navigate and excel in a TS setting. The program comprises a series of multi-day team meetings at SESYNC, long-term and structured engagement with staff, tailored cyberinfrastructure and computational support, and leadership training in the management and organization of teams for designated team leaders (two per team). The present study represents an exploratory effort to assess the GP's outcomes via a survey of its first cohort.

\section{Methods}

Study participants $(n=39)$ comprised six teams who began their program in January 2015. All respondents were a doctoral student or candidate at the start of the GP. Geographically, most GP participants attended universities in the USA: Northeast (6), South Atlantic region (7), South (3),
Midwest (5), Mountain West (3), and West (6). Globally, universities from Australia (1), Canada (6), Germany (1), and the UK (1) were represented. The first cohort's program formally ended in April 2016. In August 2016, an online, anonymous questionnaire of closed- and open-ended questions was sent to the cohort via Qualtrics online survey platform (KEW, KFD, JBP, and SMP were cohort members and developed the questionnaire but did not respond; all other authors were cohort members and did respond). The study was approved by the Texas A\&M University Institutional Review Board (IRB2016-0466) and informed consent was obtained prior to participation.

The questionnaire assessed participants' experiences with the program, team, and project (Online Resource 1). Questions were developed using past assessments and key themes from the literature to explore participants' experiences and perceptions of success, integration, challenges, benefits, training, and skills development (Cheruvelil et al. 2014; Nancarrow et al. 2013; Record et al. 2016). Success was measured as "how would you rate your team's overall success?"; integration as "how would you rate the level of integration (between disciplines) your team achieved?"; pre- and postparticipation comfort with IDR and TS as "how would rate your comfort level working in a team on an interdisciplinary project?"; and intention to continue IDR and TS as "will you pursue interdisciplinary collaborations and/or team science 
research during the next stage of your career?". All closeended questions were measured using a 5-point Likert scale. In addition to these close-ended questions, we administered the Ten-Item Personality Inventory (TIPI) (Gosling et al. 2003) to assess variation among participants and profile teams across five personality dimensions. These dimensions are as follows: extraversion (outgoingreserved), neuroticism (calm-anxious), agreeableness (sympathetic-critical), conscientiousness (dependable-disorganized), and openness to experience (open-conventional) (McCrae and Costa Jr 2010). We also compare integration and self-reported success across teams' TIPI profiles. Personality items were measured on a 7-point Likert scale (strongly disagree-strongly agree).

To measure participants' experiences with the GP, we asked, as an open-ended prompt: "what do you consider the lowlight(s) or negative takeaway(s) from your Graduate Pursuit experience?" and "what do you consider the highlight(s) or positive takeaway(s) of your Graduate Pursuit experience?". Challenges and barriers were measured with an open-ended prompt, "what challenges did your team face during the Graduate Pursuit?"; "how did your team overcome these challenges?"; "did you perceive any barriers or challenges while participating in the Graduate Pursuit?"; "how did you overcome these challenges?". Success was also measured with an openended prompt: "what factors were most important to your team's success?" and "what was missing but would have been helpful or facilitated team success?". Other openended prompts that inform our assessment were as follows: "how has the Graduate Pursuit differed from other interdisciplinary experiences or projects you have been part of?"; "what opportunities did participating in the Graduate Pursuit facilitate?"; "based on your experiences, what do you think are important principles for interdisciplinary research opportunities for graduate students and early career researchers?; and "what skills/knowledge gained from your experience will you take forward to new projects or do you think are transferable to the next step(s) of your career?"

Standard descriptive statistics and mean comparison were used to analyze and summarize quantitative items in $\mathrm{R}$ (v.3.2.1). Qualitative data were coded for emergent themes using content analysis and analyzed using NVivo qualitative data analysis software (Krippendorff 2004). Two researchers independently read and coded qualitative data and compared their coding processes to minimize bias in accordance with standard research practices (Patton 2002). Open- and close-ended measures allowed us to triangulate across different forms of data to infer how participants viewed and experienced the GP. As such, we integrate our presentation of these data in a combined results and discussion section.

\section{Results and discussion}

In total, 26 individuals of the eligible 35 responded, with at least 3 respondents per team (74\% response rate). Selfidentified demographics and disciplines of respondents are provided in Table 2. The following subsections reflect four emergent themes derived from content analysis, and we present an integration of qualitative and quantitative within these: (1) integration, disciplinary specialization, and shared purpose; (2) communication and teamwork; (3) personality, interpersonal skills, and conflict management; and (4) perceived costs and benefits.

\section{Integration, disciplinary specialization, and shared purpose}

For some GP team members, it was challenging to balance disciplinary concepts and methods and find common ground (Table 3). Despite this initial challenge, teams identified specific mechanisms and conditions that aided this necessary objective for effective cross-disciplinary research. For example, a team overcame disciplinary jargon by employing an overarching framework as a "boundary object" to better define disciplinary language and facilitate discussions (S1). Interestingly, the use of boundary objects or concepts is becoming a more common aspect of IDR and TS, but references to its use in graduate contexts is limited (McGreavy et al. 2013; Mattor et al. 2014; Pittman et al. 2016). For another team, shared knowledge of the system being investigated helped establish common ground (S2). Other teams used more traditional methods like delegating disciplinary specific work to subgroups or sub-projects (S3, S4), but not all viewed this as positive (S5).

Others identified lack of methodological integration or expertise as a significant challenge (Table 3, S6). For some

Table 2 Demographic characteristics of respondents

\begin{tabular}{lll}
\hline Gender $(N=26)$ & Females & 18 \\
Age & Males & 8 \\
& Mean & 32.6 \\
Disciplinary focus (self-identified) $)$ & Ecology & $23-54$ \\
& Environmental engineering & 4 \\
& Environmental science & 5 \\
& Geography & 4 \\
Team responses/team size & Social science & 8 \\
& Team 1 & $3 / 6$ \\
& Team 2 & $5 / 9$ \\
& Team 3 & $4 / 7$ \\
& Team 4 & $4 / 6$ \\
& Team 5 & $6 / 7$ \\
& Team 6 & $4 / 8$ \\
\hline
\end{tabular}


Table 3 Integration, disciplinary specialization, and shared purpose theme key quotes and categories

\begin{tabular}{|c|c|}
\hline Category & Key quote(s) \\
\hline Boundary objects & $\begin{array}{l}\text { "There were moments where we had to work through discipline-specific } \\
\text { jargon. We addressed this through patience with each other and the } \\
\text { socio-ecological system framework. The SESF served as a boundary object } \\
\text { and an exercise in selecting and defining the variables of interest helped to } \\
\text { work through the differences." S1 } \\
\text { "Our shared knowledge of the system was so key to smooth interaction. One } \\
\text { person might do qualitative interviews, and the other spatial ecology, but } \\
\text { given that everyone knew the social and ecological elements in a robust, but } \\
\text { general way, we could communicate the purpose of analyses, statistical tests, } \\
\text { policy implications etc." S2 }\end{array}$ \\
\hline Subgroups & $\begin{array}{l}\text { "The subgroup structure within our group was such that you were working in } \\
\text { different groups for different parts of the project. This ensured that ideas } \\
\text { were flowing better all members of the group, and we were kept up-to-date } \\
\text { instead of breaking into small groups that did not get to talk very often." S3 } \\
\text { "Identifying key sub projects and structuring them to ensure engagement of all } \\
\text { members, and synthesis across sub projects. It really seemed to be about } \\
\text { building the right framework through leadership, and then using a more } \\
\text { hands-off approach." S4 } \\
\text { "I rated the team somewhat unintegrated because we are still basically } \\
\text { functioning as two separate groups." S5 }\end{array}$ \\
\hline $\begin{array}{l}\text { Conceptual and } \\
\text { methodological integration }\end{array}$ & $\begin{array}{l}\text { "One of our case studies mixes qualitative analysis of media history with } \\
\text { quantitative analysis of agricultural response to drought. Both techniques } \\
\text { yield interesting results, but not necessarily results that make sense to } \\
\text { intertwine into one story." S6 } \\
\text { "Interestingly one of the biggest challenges I found was that some of our team } \\
\text { members were very efficient in R while others were not. This gave some } \\
\text { members a certain degree of authority over the questions being asked, } \\
\text { because they were the only ones analyzing the data. Sometimes we would } \\
\text { spend whole meetings with some people trying to explain how the data was } \\
\text { being operationalized in R (example: how they were assigning different } \\
\text { people to different groups). This sometimes made it difficult for people to } \\
\text { propose theories, because they were not } 100 \% \text { clear on how certain } \\
\text { variables were being produced." S7 } \\
\text { "Our team took quite a bit of time to figure out the best way to link our } \\
\text { individual disciplines and skill sets. I would say our level of integration } \\
\text { would be very high going forward, if we were to continue with the project } \\
\text { for another term." S8 } \\
\text { "Some members held on to their disciplinary ideas, and the context } \\
\text { surrounding these ideas very strongly, making creative integration a } \\
\text { challenge sometimes." S9 }\end{array}$ \\
\hline Expanded epistemology & $\begin{array}{l}\text { "I think I am much more open minded and able to see limitations of } \\
\text { disciplinary thought much more easily." S10a } \\
\text { "Working across disciplines exposes some of the siloed thinking that goes on } \\
\text { within each of our own fields." S10b }\end{array}$ \\
\hline
\end{tabular}

teams, this manifested as research activities becoming specialized due to member's methodological or computational expertise (e.g., coding, programming) (S7). This challenge is also identified by past assessments (e.g., Ryser et al. 2009; Pennington 2016). Participants also viewed meaningful integration of concepts and data as a challenge, but the underlying reasons varied (Table 3, S8, S9). For some, the challenge was related to differences in theoretical perspectives while others attributed this challenge to the use of different methods or analytical frameworks.
Despite these challenges, respondents reported increased comfort with IDR and TS from pre- to postparticipation (pre $M=3.62, \mathrm{SD}=1.02$; post $M=4.73$, $\mathrm{SD}=0.45 ; t(25)=5.51, p<.001, d=1.41)$. For instance, participants stated: "I think I'm much more open minded and able to see limitations of disciplinary thought much more easily" (S10a); "working across disciplines exposes some of the siloed thinking that goes on within each of our own fields" (S10b). This suggests the research structures and process implemented by the GP were by and 
large successful at facilitating teams' ability to find common ground or meaningful points of integration. Increases in disciplinary and methodological specialization will continue to create challenges for integrating and developing shared purpose in IDR and TS (National Research Council 2005; Lindenfeld et al. 2012). Yet, successful collaboration relies on finding common ground and meaningful integration. Figure 2 demonstrates this tenet as, in general, teams self-reporting high team integration report high team success. This is further demonstrated by a significant positive correlation observed between team success and integration $(r=0.58, p<0.01)$.

Integration of diverse and specialized knowledge for a shared purpose is fundamental to IDR and TS (Stokols et al. 2008). As such, interdisciplinary doctoral training must develop frameworks that support collaborative activities and disciplinary interaction to increase capacity for integrating concepts and methods and learning from other disciplines (Frodeman et al. 2017). Ultimately, building awareness of other scientific perspectives to create a shared purpose better enables students to participate in future interdisciplinary team research projects (Goring et al. 2014). Graduate students also identified issues pertaining to methods, analytical frameworks, and data analyses as barriers to integration and shared purpose. Team members with certain skills were perceived as excluding others from participating in analyses and decision-making (S7, S9). The manifestation of this issue in graduate teams is interesting considering sophisticated statistical analyses and big-data approaches are becoming more common in cross-disciplinary synthesis (Hampton et al. 2017). The implications of this perceived barrier and related issues, such as interactions between theorybased methods and data-driven analyses, is an important issue to address for the future of S-E science.

\section{Communication and teamwork}

Participants described the not only the important role of communication, but also the tension between managing communication and project momentum and workflow (Table 4). Respondents indicated several themes that facilitated effective communication: listening, respecting and incorporating diverse viewpoints, learning from other team members, and informal socialization. These contributed to a shared understanding of research activities, team goals, and individual responsibilities. Effective communication helped build clearly defined roles, trust, and effective working relationships among team members. Subsequently, this enabled teams to work through challenges and coordinate, collaboratively and iteratively, towards the completion of project tasks. In-person meetings were referenced as crucial elements of facilitating communication, social integration, and teamwork, which aligns with SESYNC's broader framework for collaboration (S17-S19). Teams that focused on continual and scheduled types of communication (either in-person or web-based) identified these regular interactions as fundamental to their success. Respondents acknowledged the value of these firsthand exchanges and the importance of them in developing communication skills, adjusting communication strategies and managing project momentum (S20, S21).

Communication is a central part to any team effort (McGreavy et al. 2015; Thompson 2009). Effective communication enables information exchange and development of relationships among team members but is rarely the focus of graduate education and training (Read et al. 2016). While several past assessments note the importance of communication, others situate communication as the central and focal element of interdisciplinary research and practice (Lindenfeld et al. 2012; McGreavy et al. 2013). Our assessment reinforces the paramount importance of communication
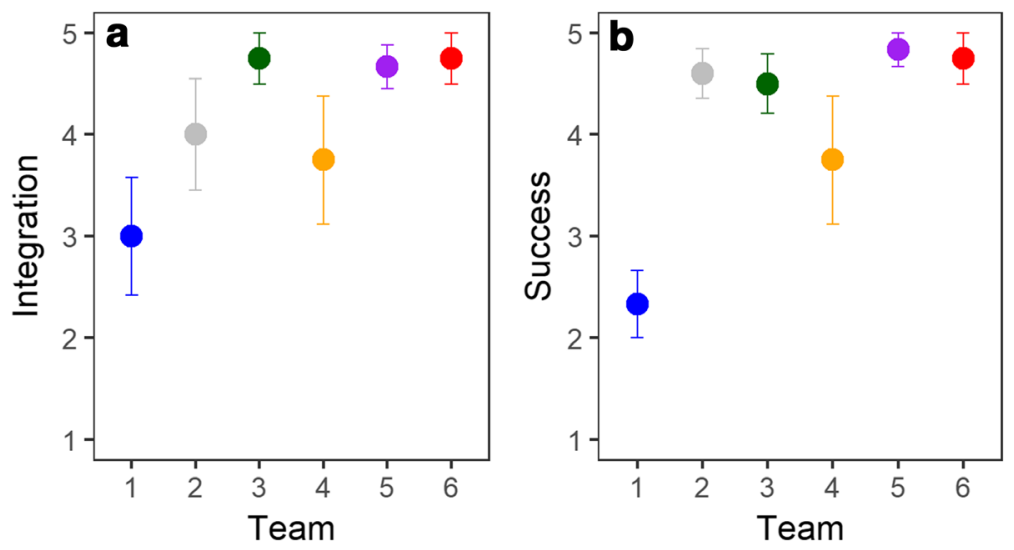

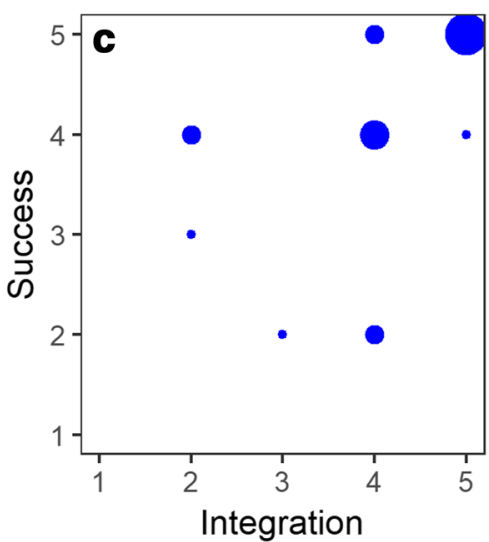

corresponds to the number of respondents). Colors correspond to each team and are consistent throughout
Fig. 2 Mean $( \pm \mathrm{SE})$ of self-reported integration and success ratings by team (Pearson's $r=0.58, p<0.01$ ) and the relationship between success and integration ratings for individual respondents (size of points 
Table 4 Communication and teamwork theme key quotes and sub-categories
In-person meetings and face-time

Momentum

Meeting design and project workflow

Informal socialization
Key quote(s)

"Clear communication, organization and team rapport were critical to our success." S11

"I learned the importance of good communication. It is not enough to assume that partners have the same goals and expectations. It is important that these goals and expectations are discussed regularly to maintain motivation and ensure positive outcomes, particularly when face-to-face meeting are limited." S12

"A related aspect of this was the strong ongoing communications among team members that fostered this teamwork and helped people know what their responsibility was and when it was due." S13

"We had regularly scheduled deadlines and phone calls and I think what has made the group successful is the open and good communication and understanding." S14

"Open, honest communication about perspectives and availability, and the ability to deliver on promises made." S15

"We dealt with this challenge by encouraging communication and by both developing a project schedule but being flexible about how it was achieved." S16

"Being able to meet in-person was crucial. The support provided by SESYNC during meetings made a big difference; having logistics taken care of allowed us to get the most out of meeting time by focusing on the work and getting to know each other in a relaxed atmosphere. The face time with SESYNC staff was also a big part of that support." S17

"Long face-to-face meetings allowed us to move past the 'frustration' stage and into the 'fine, we are frustrated, but we [should] try to figure out a solution' stage" S18

"We struggled with our paper topics/formats at the beginning but after lots of sitting in a room together and talking things out, we found a focus that worked for us" S19

"It was sometime difficult for us to keep our momentum going post-meetings when we got overwhelmed with our own work, but we tried to keep bi-weekly or monthly meetings to keep us on track." S20

"Other challenges were keeping momentum; we tried to remedy this via more frequent Skype meetings and having a 'lead' on each paper who kept people moving." S21

"I think structured and planned group discussion, quite-moment for people to reflect, and small group discussions are all very useful, especially when the discussion seems to come to an end." S22

"It was longer [previous program was much shorter, 2 weeks in person followed by a few months of follow-up], which allowed us to do higher quality work and deeper thinking about learning take-homes." S23

"Drinks and dinner together are very good way to bond us, and this bond is the key for us to work together eventually" S24

"We were all on the same page with regard to working hard during the day and enjoying a beverage together in the evenings. In other words, the informal social times in the evenings were [really] important. But a key piece to that is that all of us enjoyed it!" S25 and development of communication skills and strategies in facilitating collaboration (i.e., Stokols et al. 2008). Interdisciplinary doctoral training programs can meet this need by providing explicit communication training and support for teams. Communication is highlighted in many proposed doctoral training best practices and teamwork principles (Nancarrow et al. 2013).
Our results were similar to other assessments, which suggest that the settings, structures, and processes that support and facilitate effective communication can be as, if not more, important to the success of projects as expertise, technical skills, organization, or leadership (Bennett et al. 2018). As with most TS projects, GP team leaders served as the nexus for communication and teamwork and the GP program 


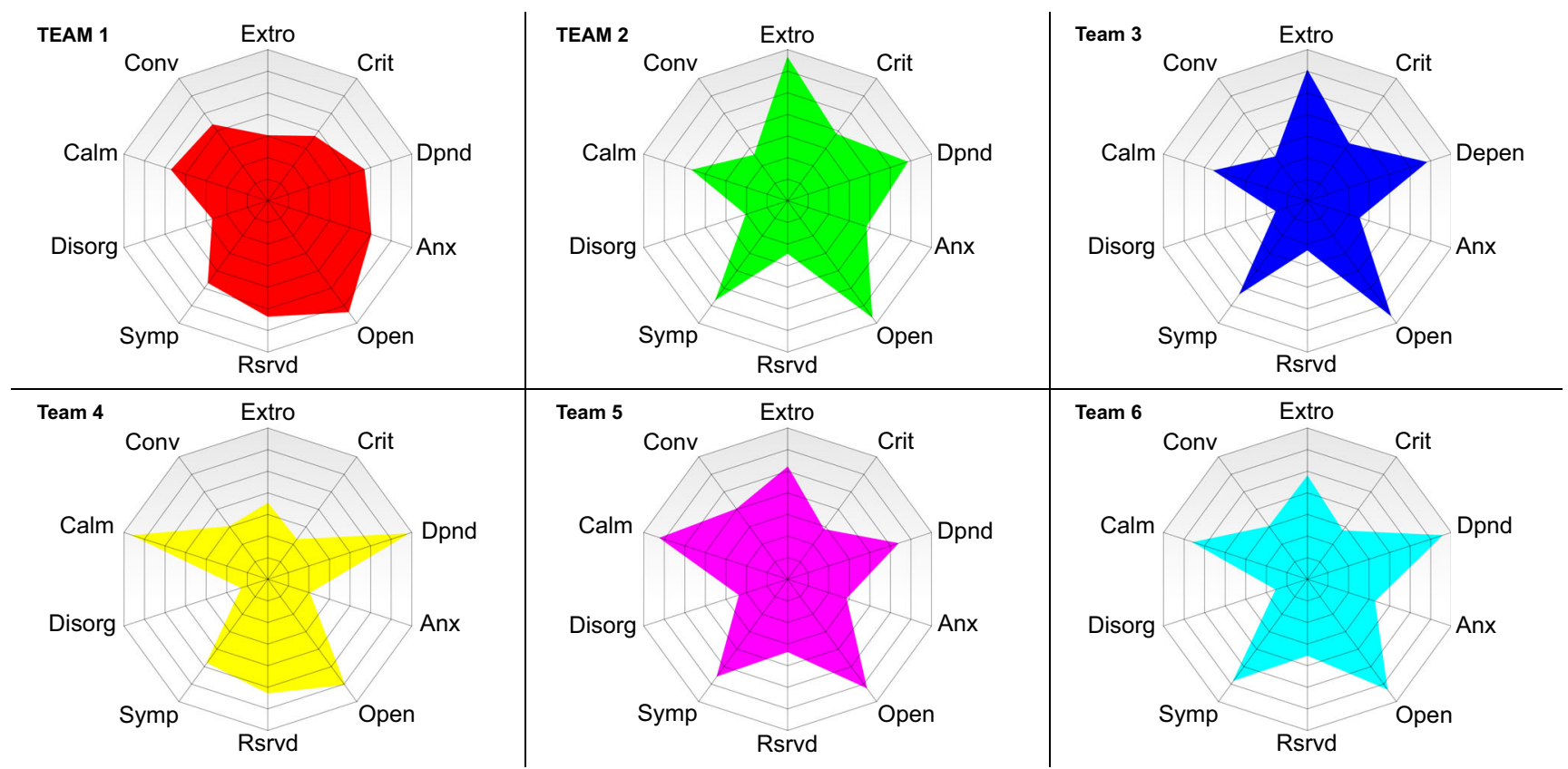

Fig. 3 Radial plot distribution of mean self-reported personality trait score per team for all personality traits. All plots scaled 1 (disagree strongly) to 7 (agree strongly). Colors correspond to each team and are consistent throughout. Teams 3, 5, and 6 self-reported high ratings of team integration and success, whereas teams 1 and 4 self-reported the lowest of both measures. Team 2 self-reported high success but moderate to low integration (see Fig. 2) director met with team leaders before and after each on-site team meeting to discuss communication and teamwork challenges and potential strategies to move the project forward. These conversations were intended to heighten awareness of potential communication gaps and to develop plans to improve teamwork, if needed. The structure and process of these scheduled and regular meetings ensured that the team leaders would continuously communicate with SESYNC and discuss among themselves the status of the project and team dynamics. SESYNC also provided team leaders with feedback on meeting agendas to ensure the effective use of time, that meeting objectives were clearly articulated, and the meeting structure and activities were designed to achieve project objectives.

From our assessment, data suggest that the support offered to team leaders by SESYNC transferred to the teams, as many of the principles and activities present are mentioned by respondents. For example, respondents stated, "...it is important that these goals and expectations are discussed regularly" (S12), "we had regularly scheduled deadlines and phone calls and I think what has made the group successful is the open and good communication and understanding." (S14), "support provided by SESYNC during meetings made a big difference; having logistics taken care of allowed us to get the most out of meeting time by focusing on the work and getting to know each other in a relaxed atmosphere." (S17), and "structured and planned group discussion...are [all] very useful." (S22). Collectively, our findings provide evidence that strategies like those offered by SESYNC and developed by GP teams, which facilitate or focus on interpersonal communication and communication tools and techniques and create a supportive communication environment, contribute to successful IDR and TS.

\section{Personality, interpersonal skills, and conflict management}

Interpersonal dynamics related to personality are a common and ubiquitous challenge of IDR and TS (Bennett et al. 2018; Molleman 2005). In general, team members who perceived others as having positive personality traits cited this as a strength and a reason for a success. For example, openness was often referenced as contributing positively to team progress and success: "openness and interest by all team members to work across boundaries" (S26), "all of us were very open to hearing each other's ideas and willing to learn from and about other disciplines" (S28), and "Any challenges our team faced we overcame by being completely open and honest" (S29). This theme was also reflected in teams' ability to manage conflict (S32-S35).

Results from the TIPI corroborate these findings as moderate to high ratings of extraversion $(4.73, \mathrm{SD}=$ $1.87)$, agreeableness $(M=5.12, \mathrm{SD}=1.12)$, conscientiousness $(M=5.96, \mathrm{SD}=0.95)$, emotional stability $(M=5.12$, 
Table 5 Personality, interpersonal skills, and conflict management theme key quotes and sub-categories

\begin{tabular}{|c|c|}
\hline Category & Key quote(s) \\
\hline \multirow[t]{6}{*}{$\begin{array}{l}\text { Openness and } \\
\text { conscientiousness }\end{array}$} & $\begin{array}{l}\text { "Openness and interest by all team members to work across boundaries and to be } \\
\text { respectful/ acknowledge different types of research" S } 26\end{array}$ \\
\hline & $\begin{array}{l}\text { "Also, generally being a good-natured team of overachievers. I am sure most teams } \\
\text { are like this, but we did not end up having any abrasive personalities and } \\
\text { everybody pulled their weight - we do not have to nag or wait up for anyone." S27 }\end{array}$ \\
\hline & $\begin{array}{l}\text { "All of us were very open to hearing each other's ideas and willing to learn from and } \\
\text { about other disciplines. I think the lack of ego and willingness to cooperate were } \\
\text { extremely helpful in making our team successful." S28 }\end{array}$ \\
\hline & $\begin{array}{l}\text { "Any challenges our team faced we overcame by being completely open and honest. } \\
\text { I have never been on any team before where everyone was so upfront about their } \\
\text { abilities and shortcomings." S29 }\end{array}$ \\
\hline & $\begin{array}{l}\text { "Attitudes. We have a very friendly and fun group. We were all respectful of each } \\
\text { other's ideas and time." S30 }\end{array}$ \\
\hline & "Good personalities on the team who became friends." S31 \\
\hline \multirow[t]{4}{*}{ Task conflict } & $\begin{array}{l}\text { "We do not have to nag or wait up for anyone; all of us were very open to hearing } \\
\text { each other's ideas and willing to learn from and about other disciplines. I think the } \\
\text { lack of ego and willingness to cooperate was extremely helpful in making our } \\
\text { team successful." S32 }\end{array}$ \\
\hline & $\begin{array}{l}\text { "We often got stuck rehashing the same point over and over. I think this was largely } \\
\text { because one or two team members were hesitant to move forward for various } \\
\text { reasons. This often kept us at a standstill. We worked through it by giving those } \\
\text { team members the space to air their concerns and offer alternative paths forward. } \\
\text { Even if the team disagreed, the concerned team member usually felt comfortable } \\
\text { moving forward since they had a chance to be heard. Occasionally things came to } \\
\text { a head and we had to push forward even without their support, but this at times } \\
\text { strained relationships" S33 }\end{array}$ \\
\hline & $\begin{array}{l}\text { "Our team faced the challenge determining the most interesting direction of the } \\
\text { research and bringing everyone on the table, we spent a lot of time to bring } \\
\text { everyone on the same page so that our conversation made sense to all of us." S34 }\end{array}$ \\
\hline & $\begin{array}{l}\text { "Keeping the big picture in mind helped with the former and learning about the } \\
\text { methods and developing trust helped with the latter." S35 }\end{array}$ \\
\hline
\end{tabular}

$\mathrm{SD}=1.30)$, and openness $(M=4.77, \mathrm{SD}=0.76)$ were reported across participants and within teams (Fig. 3). Openness was significantly correlated with extraversion $(r=0.48)$ and conscientiousness $(r=0.46)$, which are further evidenced in the qualitative data as contributing to a team's ability to manage and overcome challenges (Table 5, S26-S31). Teams with members sharing similar personality traits rated the overall success of their project higher compared with teams with more disparate personality traits (Figs. 2 and 3). For example, team 1 ranked lowest in terms of integration and success (Fig. 2) and contained the most diverse personality traits (round shape versus star shaped in Fig. 3).

In terms of personality traits, assessments of later-career collaborations find that team performance, conflict resolution, and decision-making are affected by dominant personalities, egocentrism, and associated power dynamics (National Research Council 2015; Mattor et al. 2014). However, GP participants did not mention these negative factors. For example, two respondents noted, "we didn't end up having any abrasive personalities and everybody pulled their weight"
(S27) and "lack of ego and willingness to cooperate were extremely helpful in making our team successful" (S28). That is, in general, teams reported amiable interactions and positive progress towards conflict resolution. The contrast between later-career and GP experiences is an important finding. At the graduate stage, overt power dynamics and egoism seem to be less of an issue or challenge. It is possible to infer that by providing training and experience with IDR/TS at the graduate career stage, positive team dynamics, relationship building, and conflict resolution skills could be ingrained and persist to later-career collaborations. That is, by training graduate students at a formative time in their career, it is possible that, apart from enabling IDR/TS capacity-building, programs like the SESYNC GP limit the potential for negative dimensions of personality traits to stagnate or impair collaborative S-E research.

\section{Perceived costs and benefits}

Respondents viewed the benefit/cost ratio of GP participation favorably. When asked if they would pursue future 
Table 6 Perceived costs and benefits theme key quotes and sub-categories
Networking

Expanded epistemology

Career benefits

Time management
Key quote(s)

"The greatest challenge personally was the growing disconnect between my own academic work and that of the Grad Pursuit topic. The support from my advisor for my involvement in the Grad Pursuit waned significantly. Also, I believe I might have been better waiting another year to have allowed for more clarity regarding my own research topic, which turned in a very different direction from the SESYNC project. I greatly underestimated the time required and think we could have made some better choices regarding data sources. I do not think I really overcame these challenges, rather the Grad Pursuit became sort of a side project, somewhat unrelated, and something rather invisible to my overall graduate experience." S36

"My advisor was encouraging of this experience but maintained the same demands on my time, so the main challenge was to both meet my advisor's objectives and complete my team responsibilities" S37

"Sometimes people got flooded with work, but I think everyone has been open about their availability and timelines and no one has been negative about anyone else's contribution" S38

"I definitely have negative input from my advisor about my SESYNC work because it's not my dissertation, but it is so enjoyable to work on something with a team as opposed to working alone on my dissertation (said advisor is frequently MIA)." S39

"The most useful component of the project was the building of a network of researchers" S40

"I think I am much more open minded and able to see limitations of disciplinary thought much more easily" S41

"I also feel like I have a better general knowledge of social science techniques and therefore can have a conversation with social science experts" S42

"It is an eye-opening experience, the exposure and lessons learned from this pursuit will affect my whole career. I am excited about future interdisciplinary research." S43

"I had a hard time managing my time. I spent a considerable amount of time on this project but was not able to use any of it towards my degree requirements. I was able to overcome them because my advisor was understanding and required less of me to graduate." S44

"It was very time-intensive, more so than I really had the resources for as a graduate student" S45

"This was a lot of freaking work in addition to my dissertation" S46 interdisciplinary research based on their experience with the GP, most respondents indicated they were very likely to do so $(M=4.71, \mathrm{SD}=0.72 ; 1$, very unlikely, 5, very likely). We interpret this as respondents' perceiving that the costs of interdisciplinary research are justified given the benefits received or that will be received. The most common perceived cost was the amount of work and time required for the project while having other graduate program demands (reported by $38 \%$ of respondents). Content analysis revealed two other primary costs (or barriers): disconnect from dissertation research and strained relationship with graduate advisor (Table 6). Importantly, respondents perceived these costs as interrelated (S36).

In terms of past assessments, these costs are unique to the graduate student experience (Morse et al. 2007; Read and Garcia 2015). Content analysis further revealed three primary benefits associated with the GP experience: developing relationships with other early-career researchers, being exposed to and gaining appreciation for different disciplines, and increased confidence and comfort moving across and integrating with disciplines. Participants also referenced benefits such as networking (S40), expanded epistemology (S41), and increased exposure to other disciplines (S42). These results help to explain the increased comfort with interdisciplinary research that participants expressed from pre- to post-GP.

Surprisingly, respondents did not commonly mention research outcomes (conference presentation, publications, job talks, technical reports, etc.) as a benefit of the GP, although teams developed several tangible research outcomes (Online Resource 2) (Keck et al. 2017). Often, the success of academic research is gauged by production of peer-reviewed manuscripts, with IDR/TS groups tending to produce fewer publications initially but more in the long- 
Table 7 Research outcomes of the SESYNC Graduate Pursuit's first cohort (as of December 2018)

\begin{tabular}{|c|c|c|c|c|c|c|}
\hline Research outcomes & Team 1 & Team 2 & Team 3 & Team 4 & Team 5 & Team 6 \\
\hline \multicolumn{7}{|l|}{ Peer-reviewed manuscript } \\
\hline Accepted & - & 2 & 2 & 3 & 2 & 1 \\
\hline In-review & - & - & - & - & - & 1 \\
\hline In-preparation & 1 & 1 & 1 & - & - & 2 \\
\hline Conference presentation & 2 & 6 & 2 & 1 & 2 & 3 \\
\hline Stakeholder presentation & - & 1 & - & - & - & 1 \\
\hline \multicolumn{7}{|l|}{ Policy brief/technical report } \\
\hline In-preparation & - & - & - & - & 1 & - \\
\hline Planned & - & 1 & - & - & - & 1 \\
\hline \multicolumn{7}{|l|}{ Public dataset/database } \\
\hline Available & - & - & - & 1 & - & - \\
\hline In-development & - & - & - & 1 & 1 & - \\
\hline
\end{tabular}

term (Hall et al. 2012). Respondents may not have recognized the potential of their project to yield scholarly publications, were not yet focused on these outcomes, or simply felt they were secondary or resulting from more primary benefits offered by IDR/TS. Nevertheless, each team reported various research outcomes stemming from their GP project, which aligns with SESYNC's goal of facilitating successful collaborations and research outcomes (Table 7).

Many of the costs and benefits reported here align with those identified by other assessments, which also describe benefits associated with training, salary, satisfaction, publications, knowledge for policy, and future funding potential (Goring et al. 2014). Potential costs include losses of credit and academic freedom, lower publication impact, and time. As with our results, time was the major cost identified, with networking or relationships with other early-career researchers cited as a major benefit. GP respondents, being graduate students, identified additional costs, such as the disconnect from dissertation research and advisor-advisee relationship, and benefits associated with increased confidence, comfort, and appreciation for IDR/TS. These added costs and benefits enrich our previous understanding of the graduate experience with IDR/TS and provide additional considerations for the design of doctoral training programs. They also provide relevant information for early-career researchers who are interested in engaging with IDR/TS research.

\section{Conclusion}

Our assessment and identification of four emergent themes highlights areas that current and future training and research programs can use to focus IDR and TS skills development, research efficacy, and collaborative experiences.
Reported benefits of the GP include independently conducting research (without faculty supervision), developing interpersonal skills applicable to collaborative settings, networking with other early-career researchers, and exposure to and comfort with IDR/TS. Findings reiterate the need for, and benefits of, developing effective interpersonal communication skills and communication strategies, which should be viewed as foundational components of IDR/TS success (Bennett et al. 2018). While respondents reported being open to different ideas and perspectives, a main challenge identified was difficulty integrating divergent methods or analytical techniques, which was coupled with time management challenges and balancing other graduate responsibilities (Hampton 2017; Morse et al. 2007).

The autonomy and relatively unsupervised research environment of the GP provided a "learn-by-doing" approach that facilitated participants' ability to actively propose, develop, lead, and complete an interdisciplinary S-E project within a TS setting (Roy et al. 2013). Broadly, our assessment observed that learn-by-doing conditions can be important facilitators of successful graduate training. Development of learnby-doing frameworks may be an essential expansion and evolution of interdisciplinary graduate training programs (Biancani et al. 2018). This conclusion reflects the practical, independent, long-term, and iterative research framework enacted by SESYNC (Fig. 1).

Uniquely, the model of independent IDR used by the GP provides students with a safe environment to take risks, where failure is not detrimental to their graduate degree. The length of the GP (12-18 months) reflected the nature of most interdisciplinary research collaborations that respondents will encounter throughout their research careers. We are aware of no other graduate training program that has explicitly developed a setting and expectations that mimic conditions encountered beyond 
graduate school. This approach may serve as a new template for future training programs, which tangentially addresses a recommended best practice of developing a student's sense of ownership of a research project (Graybill et al. 2006; Roy et al. 2013).

Moreover, GP projects required ongoing interaction with team members, allowing respondents to put their skills to the test in real time. Such an environment and timeframe, in turn, facilitated iterative learning of technical skills (computational, analytical), soft skills (communication, teamwork), and project management. At the individual level, our findings stress the importance of developing these skillsets to foster effective research, positive interactions, and beneficial experiences (Blickley et al. 2013; Cannon et al. 1996). While developing relevant computational and analytical skills has become a focal aspect of graduate program curricula, equally important are teamwork facilitation, project management, and interpersonal skills training (Hampton et al. 2017; Meyer et al. 2015). These and other soft skills - e.g., interpersonal communication, listening, and "playing well with others"-are critical but often under-nourished elements of training for graduate students and early-career scientists. Students often learn these skills ad hoc and through trial-and-error. In not developing these skills, graduate programs and advisors may be putting students at a disadvantage as they transition into the S-E profession as independent researchers and practitioners (Carr et al. 2018).

Collectively, our findings suggest a need and opportunity for both program-level elements (long-term, independent, and iterative) and individual-level elements (technical, interpersonal, and management skills development) to become foundational components of interdisciplinary graduate training. While this is a challenge for conventional graduate programs, which focus on scientific and technical training, our findings suggest practical soft skills are crucial to expanding IDR and TS capacity. In this regard, training programs that are independent of a university may be more beneficial, particularly given their potential to mimic the expectations and responsibilities that students will likely encounter in future, postgraduate collaborations. Deliberately prioritizing soft skills training at the same level as technical and analytical skills will further accelerate and expand interdisciplinary capacity and the establishment of a diverse research community capable of addressing the complexity of contemporary S-E issues.

Acknowledgements We thank C. Begg, P. Bitterman, B. Breyer, M. Burke, K. Ernst, E. Esch, E. Fuller, J. Hoyle, H. Huber-Stearns, S. Jones, K. Lyon, K. Mango, K. Smith, and A. Tecza for their assistance. We thank J. Kramer, G. Kyle, and M. Palmer for their support. We also thank our anonymous reviewers.

Funding information This work was facilitated by the National SocioEnvironmental Synthesis Center (SESYNC) under funding received from the National Science Foundation DBI-1052875.
Open Access This article is distributed under the terms of the Creative Commons Attribution 4.0 International License (http:// creativecommons.org/licenses/by/4.0/), which permits unrestricted use, distribution, and reproduction in any medium, provided you give appropriate credit to the original author(s) and the source, provide a link to the Creative Commons license, and indicate if changes were made.

\section{References}

Baron JS, Specht A, Garnier E, Bishop P, Campbell CA, Davis FW, Fady B, Field D, Gross LJ, Guru SM, Halpern BS, Hampton SE, Leavitt PR, Meagher TR, Ometto J, Parker JN, Price R, Rawson CH, Rodrigo A, Sheble LA, Winter M (2017) Synthesis centers as critical research infrastructure. Biosci 67:750-759. https://doi.org/10.1093/ biosci/bix053

Bennett LM, Gadlin H, Marchand C (2018) Collaboration and team science: a field guide, $2 \mathrm{n}$ edn. National Institutes of Health, Washington http://teamscience.nih.gov

Biancani S, Dahlander L, McFarland DA, Smith S (2018) Superstars in the making? The broad effects of interdisciplinary centers. Res Policy 47:543-557. https://doi.org/10.1016/j.respol.2018.01.014

Blickley JL, Diener K, Garbach K, Lacher I, Meek MH, Porensky LM et al (2013) Graduate student's guide to necessary skills for nonacademic conservation careers. Conserv Biol 27:24-34. https://doi. org/10.1111/j.1523-1739.2012.01956.x

Bosque-Pérez NA, Klos PZ, Force JE, Waits LP, Cleary K, Rhoades P, Galbraith SM, Brymer ALB, O'Rourke M, Eigenbrode SD, Finegan B, Wulfhorst JD, Sibelet N, Holbrook JD (2016) A pedagogical model for team-based, problem-focused interdisciplinary doctoral education. Biosci 66:477-488. https://doi.org/10.1093/biosci/ biw042

Cannon JR, Dietz JM, Dietz LA (1996) Training conservation biologists in human interaction skills. Conserv Biol 10:1277-1282. https://doi. org/10.1046/j.1523-1739.1996.10041277.x

Carr G, Loucks DP, Blöschl G (2018) Gaining insight into interdisciplinary research and education programmes: a framework for evaluation. Res Policy 47:35-48. https://doi.org/10.1016/j.respol.2017.09. 010

Cheruvelil KS, Soranno PA, Weathers KC, Hanson PC, Goring SJ, Filstrup CT, Read EK (2014) Creating and maintaining highperforming collaborative research teams: the importance of diversity and interpersonal skills. Front Ecol Environ 12:31-38. https://doi. org/10.1890/130001

Clark SG, Steen-Adams MM, Pfirman S, Wallace RL (2011) Professional development of interdisciplinary environmental scholars. J Environ Stud Sci 1:99-113. https://doi.org/10.1007/s13412-011-0018-z

Colón-Rivera RJ, Marshall K, Soto-Santiago FJ, Ortiz-Torres D, Flower CE (2013) Moving forward: fostering the next generation of Earth stewards in the STEM disciplines. Front Ecol Environ 11:383-391. https://doi.org/10.1890/120307

Demharter S, Pearce N, Beattie K, Frost I, Leem J, Martin A, Oppenheimer R, Regep C, Rukat T, Skates A, Trendel N, Gavaghan DJ, Deane CM, Knapp B (2017) Ten simple rules for surviving an interdisciplinary $\mathrm{PhD}$. PLoS Comput Biol 13: e1005512. https://doi.org/10.1371/journal.pcbi. 1005512

Edelenbos J, Bressers N, Vandenbussche L (2017) Evolution of interdisciplinary collaboration: what are stimulating conditions? Sci Public Policy 44:451-463. https://doi.org/10.1093/scipol/scw035

Frodeman R, Klein J, Pacheco RCS (2017) Oxford handbook of interdisciplinarity, 2nd edn. Oxford University Press, Oxford

Golde CM, Gallagher HA (1999) The challenges of conducting interdisciplinary research in traditional doctoral programs. Ecosystems 2: 281-285. https://doi.org/10.1007/s100219900076 
Goring SJ, Weather KC, Dodds WK, Soranno PA, Sweet LC, Cheruvelil KS et al (2014) Improving the culture of interdisciplinary collaboration in ecology by expanding measures of success. Front Ecol Environ 12:39-47. https://doi.org/10.1890/120370

Gosling SD, Rentfrow PJ, Williams SB (2003) A very brief measure of the big-five personality domains. J Res Pers 37:504-528. https://doi. org/10.1016/S0092-6566(03)00046-1

Graesser AC, Fiore SM, Greiff S, Andrews-Todd J, Foltz PW, Hesse FW (2018) Advancing the science of collaborative problem solving. Psychol Sci Public Interest 19:59-92. https://doi.org/10.1177/ 1529100618808244

Graybill JK, Dooling S, Shandas V, Withey J, Greve A, Simon GL (2006) A rough guide to interdisciplinarity: graduate student perspectives. Biosci 56:757-763. https://doi.org/10.1641/00063568(2006)56[757:ARGTIG]2.0.CO

Guston DH (2001) Boundary organizations in environmental policy and science: An introduction. Sci Technol Hum Values 26:399-408. https://www.jstor.org/stable/690161. Accessed 09 Oct 2018

Hall KL, Stokes D, Stipelman BA, Vogel AL, Feng A, Masimore B et al (2012) Assessing the value of team science: a study comparing center- and investigator-initiated grants. Am J Prev Med 42:157163. https://doi.org/10.1016/j.amepre.2011.10.011

Hampton SE, Jones MB, Wasser LA, Schildhauer MP, Supp SR, Brun J, Hernandez RR, Boettiger C, Collins SL, Gross LJ, Fernández DS, Budden A, White EP, Teal TK, Labou SG, Aukema JE (2017) Skills and knowledge for data-intensive environmental research. Biosci 67:546-557. https://doi.org/10.1093/biosci/bix025

Heemskerk M, Wilson K, Pavao-Zuckerman M (2003) Conceptual models as tools for communication across disciplines. Conserv Ecol 7

Jacobs JA, Frickel S (2009) Interdisciplinarity: a critical assessment. Annu Rev Sociol 35:43-65. https://doi.org/10.1146/annurev-soc070308-115954

Keck A-S, Sloane S, Liechty JM, Fiese BH, Donovan SM (2017) Productivity, impact, and collaboration differences between transdisciplinary and traditionally trained doctoral students: a comparison of publication patterns. PLoS One 12:e0189391. https://doi.org/10. 1371/journal.pone.0189391

Killion AK, Sterle K, Bondank EN, Drabik JR, Bera A, Alian S, Goodrich KA, Hale M, Myer RA, Phung Q, Shew AM, Thayer AW (2018) Preparing the next generation of sustainability scientists. Ecol Soc 23. https://doi.org/10.5751/ES-10395-230439

Krippendorff K (2004) Content analysis: an introduction to its methodology, $2 n$ edn. Sage, Thousand Oaks

Landon AC, van Riper CJ, Angeli NF, Fitgerald DB, Neam KD (2015) Growing transdicisplinary roots in the Peruvian Amazon: lessons from the field. J Transdiscipl Environ Stud 14:2-12

LePine JA, Buckman BR, Crawford ER, Methot JR (2011) A review of research on personality in teams: accounting for pathways spanning levels of theory and analysis. Hum Resour Manag Rev 21:311-330. https://doi.org/10.1016/j.hrmr.2010.10.004

Lindenfeld LA, Hall DM, McGreavy B, Silka L, Hart D (2012) Creating a place for environmental communication research in sustainability science. Environ Commun 6:23-43. https://doi.org/10.1080/ 17524032.2011.640702

Mattor K, Betsill M, Huayhuaca C, Huber-Stearn H, Jedd T, Sternlieb F et al (2014) Transdisciplinary research on environmental governance: a view from the inside. Environ Sci Pol 42:90-100. https:// doi.org/10.1016/j.envsci.2014.06.002

McCrae RR, Costa PT Jr (2010) The five-factor theory of personality. In: John OP, Robins RW, Pervin LA (eds) Handbook of personality: theory and research, 3rd edn. Guilford Press, New York, pp 159-181

McGreavy B, Hutchins K, Smith H, Lindenfeld L, Silka L (2013) Addressing the complexities of boundary work in sustainability science through communication. Sustainability 5:4195-4221. https:// doi.org/10.3390/su5104195
McGreavy B, Lindenfeld L, Bieluch KH, Silka L, Leahy J, Zoellick B (2015) Communication and sustainability science teams as complex systems. Ecol Soc:20. https://doi.org/10.5751/ES-06644-200102

Meyer SR, Levesque VR, Bieluch KH, Johnson ML, McGreavy B, Dreyer S, Smith H (2015) Sustainability science graduate students as boundary spanners. J Environ Stud Sci 6:344-353. https://doi. org/10.1007/s13412-015-0313-1

Molleman E (2005) Diversity in demographic characteristics, abilities and personality traits: do faultlines affect team functioning? Group Decis Negot 14:173-193. https://doi.org/10.1007/s10726-0056490-7

Morse WC, Nielsen-Pincus M, Force JE, Wulfhorst JD (2007) Bridges and barriers to developing and conducting interdisciplinary graduate student team research. Ecol Soc 12

Moslemi JM, Capps KA, Johson MS, Mual J, McIntyre PB, Melvin AM et al (2009) Training tomorrow's environmental problem solvers: an integrative approach to graduate education. Biosci 59:514-521. https://doi.org/10.1525/bio.2009.59.6.10

Nancarrow SA, Booth A, Ariss S, Smith T, Enderby P, Roots A (2013) Ten principles of good interdisciplinary teamwork. Hum Resour Health 11:19. https://doi.org/10.1186/1478-4491-11-19

National Research Council (2005) Facilitating interdisciplinary research. National Academies Press, Washington. https://doi.org/10.17226/ 11153

National Research Council (2015) Enhancing the effectiveness of team science. National Academies Press, Washington. https://doi.org/10. 17226/19007

Newswander LK, Borrego M (2009) Engagement in two interdisciplinary graduate programs. High Educ 58:551-562. https://doi.org/10.1007/ s10734-009-9215-Z

Palmer MA, Kramer JG, Boyd J, Hawthorne D (2016) Practices for facilitating interdisciplinary synthetic research: the National SocioEnvironmental Synthesis Center (SESYNC). Curr Opin Environ Sustain 19:111-122. https://doi.org/10.1016/j.cosust.2016.01.002

Patton MQ (2002) Qualitative research and evaluation methods. Sage, Thousand Oaks

Peeters MA, van Tuijl H, Rutte CG, Reymen I (2006) Personality and team performance: a meta-analysis. Eur J Pers 20:377-396. https:// doi.org/10.1002/per.588

Pennington DD (2016) A conceptual model for knowledge integration in interdisciplinary teams: orchestrating individual learning and group processes. J Environ Stud Sci 6:300-312. https://doi.org/10.1007/ s13412-015-0354-5

Pittman J, Tiessen H, Montaña E (2016) The evolution of interdisciplinarity over 20 years of global change research by the IAI. Curr Opin Environ Sustain 19:87-93. https://doi.org/10.1016/j.cosust.2015.12.004

Read L, Garcia M (2015) Water diplomacy: perspectives from a group of interdisciplinary graduate students. J Contemp Water Res Educ 155: 11-18. https://doi.org/10.1111/j.1936-704X.2015.03191.x

Read EK, O'Rourke M, Hong GS, Hanson PC, Winslow LA, Crowley S et al (2016) Building the team for team science. Ecosphere 7:1-9. https://doi.org/10.1002/ecs2.1291

Record S, Ferguson PFB, Benveniste E, Graves RA, Pfeiffer VW, Romolini M, Yorke CE, Beardmore B (2016) Graduate students navigating social-ecological research: insights from the long-term ecological research network. Ecol Soc 21. https://doi.org/10.5751/ ES-08111-210107

Rhoten D, Parker A (2004) Risks and rewards of an interdisciplinary research path. Science 306:2046. https://doi.org/10.1126/science. 1103628

Roy ED, Morzillo AT, Seijo F, Reddy SMW, Rhemtulla JM, Milder JC et al (2013) The elusive pursuit of interdisciplinarity at the humanenvironment interface. Biosci 63:745-753. https://doi.org/10.1525/ bio.2013.63.9.10

Ryser L, Halseth G, Thien D (2009) Strategies and intervening factors influencing student social interaction and experiential learning in an 
interdisciplinary research team. Res High Educ 50:248-267. https:// doi.org/10.1007/s11162-008-9118-3

Stokols D, Hall KL, Taylor BK, Moser RP (2008) The science of team science: overview of the field and introduction to the supplement. Am J Prev Med 35:S77-S89. https://doi.org/10.1016/j.amepre.2008.05.002

Thompson JL (2009) Building collective communication competence in interdisciplinary research teams. J Appl Commun Res 37: 278-297. https://doi.org/10.1080/00909880903025911

Tress G, Tress B, Fry G (2007) Analysis of the barriers to integration in landscape research projects. Land Use Policy 24:374-385. https:// doi.org/10.1016/j.landusepol.2006.05.001
Tress B, Tress G, Fry G (2009) Integrative research on environmental and landscape change: $\mathrm{PhD}$ students' motivations and challenges. J Environ Manag 90:2921-2929. https://doi.org/10.1016/j.jenvman. 2008.03.015

Wallen KE (2017) Focusing on structure and process to integrate and mainstream the social sciences in conservation. Conserv Biol 31: 724-726. https://doi.org/10.1111/cobi.12871

Publisher's note Springer Nature remains neutral with regard to jurisdictional claims in published maps and institutional affiliations. 